\title{
A Wikipédia ou uma outra/nova forma do conjunto dos saberes: Uma possível abordagem discursiva
}

\author{
Larissa Scotta*
}

Resumo: Neste artigo apresentamos reflexões desenvolvidas em nossa dissertação de Mestrado, onde propusemos pensar o sítio virtual Wikipédia, conhecido como a 'enciclopédia completa', como uma outra/nova forma do conjunto dos saberes que estaria surgindo na contemporaneidade. Para tanto, ancoramo-nos nos pressupostos da Análise de Discurso francesa e da História das Ideias.

Palavras-chave: Enciclopédia; 'coisas a saber'; Wikipédia.

\section{Introdução}

O objetivo deste artigo é o de apresentar reflexões desenvolvidas em nossa dissertação de Mestrado ${ }^{1}$, cujo problema de pesquisa tem como foco a passagem que entendemos existir de uma totalidade (ilusória) dos saberes, que seria construída discursivamente nas enciclopédias espacialmente circunscritas $^{3}$, para uma impossibilidade de se construir uma totalidade como esta no sítio virtual Wikipédia ${ }^{4}$, considerado a 'enciclopédia completa'.

Colocando-nos em uma posição teórica de entremeio da Análise de Discurso de orientação francesa com a História das Ideias, e partindo de uma leitura da história do enciclopedismo, propusemos conceber a Wikipédia, este "sítio [site] significante" (cf. Orlandi, 2004) de mais de 10 milhões de verbetes ${ }^{5}$ cuja principal característica é a escrita colaborativa, não como uma enciclopédia, tal como é apresentada e habitualmente conhecida, mas como uma nova/outra forma do conjunto dos saberes que estaria surgindo na contemporaneidade.

\footnotetext{
* Mestre em Letras - Estudos Linguísticos, pelo PPGL/UFSM, sob orientação da Prof. ${ }^{a}$ Dr. Amanda Eloina Scherer. E-mail: lariscotta@yahoo.com.br

1 Título: Da enciclopédia enquanto um círculo que se fecha à Wikipédia enquanto uma rede que abre: um gesto interpretativo. Dissertação defendida em março de 2008 e realizada sob orientação da Prof. ${ }^{a}$ Dr. Amanda Eloina Scherer, do Programa de Pós-Graduação em Letras da UFSM.

3 As versões impressa, em cd-rom, dvd-rom e on-line não-colaborativas.

${ }^{4}$ Site em Língua Portuguesa: <http://pt.wikipedia.org>.

5 Página da Wikipédia em Língua Inglesa.

Disponível em: <http://en.wikipedia.org/wiki/Wikipedia>. Acesso em 15.out.2008.
} 


\section{Do círculo à rede: um gesto interpretativo}

O ponto de partida da reflexão por nós realizada foi o entendimento de que estaria circulando um discurso sobre a Wikipédia, em sua própria versão em Língua Portuguesa, em reportagens e matérias midiáticas, em blogs e portais eletrônicos, entre outros, o qual estaria fazendo a Wikipédia significar como a enciclopédia que poderia 'solucionar o problema' até então incontornável da não-apreensão de todos os saberes em um só lugar.

A fim de exemplificar tal discurso, trazemos alguns enunciados em que este estaria se fazendo presente:

A Wikipédia contém uma vasta quantidade de informação sobre os mais variados assuntos, para não dizer todos. (presente na Página de boas-vindas da versão em Lingua Portuguesa da Wikipédia)

Imagine um mundo onde é dada a qualquer pessoa a possibilidade de ter livre acesso ao somatório de todo o conbecimento bumano. É isto que estamos a fazer. (presente na página de um usuário que edita a Wikipédia)

Dois mil e trezentos anos depois do sonbo de reunir todo o conbecimento bumano na Biblioteca de Alexandria, o século XXI parece estar perto de chegar lá. Criou no meio digital o maior fenômeno editorial dos tempos modernos, a maior fonte de referência do mundo (...) (extraído da reportagem "A enciclopédia pop", da Revista Época de 23 jan. 2006)

Nestes enunciados e em outros encontrados, estaria sendo alimentado o imaginário de que o desejo de 'tudo abarcar', que vem inquietando gerações desde o desaparecimento da mítica Biblioteca de Alexandria, pudesse finalmente se concretizar neste momento em que as novas tecnologias de informação e comunicação nos colocam frente a uma multitude de 'coisas a saber' (cf. Pêcheux, 1997) nunca antes vista.

Partindo da afirmação de Orlandi (2004, p. 71) de que "toda fala resulta de um efeito de sustentação no já dito" e de que todo discurso não é um sistema fechado em si mesmo, mas sim "uma junção de fragmentos de dizeres outros que o atravessam" (Dias, 2006, p. 89), entendemos que este discurso sobre a Wikipédia traria em si uma memória de discursos outros, que também apontariam para este desejo do 'saber total' nas enciclopédias. Nesse sentido, poderíamos afirmar que o discurso em questão teria suas raízes no passado, na Biblioteca de Alexandria e no próprio enciclopedismo ocidental, que também seria atravessado pelo ideal da totalização dos saberes.

O que entendemos ser preciso destacar, não obstante, é o que estaria levando os sujeitos a terem este gesto de interpretação na atualidade. Para nós, seriam a capacidade de memória praticamente ilimitada da Web e a abertura à edição colaborativa da Wikipédia que alimentariam este imaginário da 
'enciclopédia completa'. Para alguns sujeitos, os avanços tecnológicos e a consequente mudança na materialidade da enciclopédia, das versões limitadas espacialmente para a versão da Wikipédia, poderiam superar a necessidade deste instrumento tecnológico de conciliar a ambição à exaustividade com a exigência da seletividade, imposta, num certo sentido, por seu espaço circunscrito.

Em relação a esta questão, faz-se necessário considerar que as enciclopédias até então existentes, embora herdeiras da utopia de poder 'tudo abarcar', não podem conter em seu escopo a totalidade dos saberes, de modo que caberia ao enciclopedista selecionar, recortar em meio à infinidade de 'coisas a saber', algumas destas. Este gesto de 'seleção', de 'delimitação' do que poderia ou não fazer parte da enciclopédia pode ser explicitado a partir do que Pêcheux e Fuchs (1997) afirmam sobre a enunciação em geral. Segundo os autores,

[...] os processos de enunciação consistem em uma série de determinações sucessivas pelas quais o enunciado se constitui pouco a pouco e que têm por característica colocar o 'dito' e em conseqüência rejeitar o 'não-dito'. A enunciação equivale pois a colocar fronteiras entre o que é 'selecionado' e tornado preciso aos poucos (através do que se constitui o 'universo do discurso'), e o que é rejeitado. Desse modo se acha, pois, desenhado num espaço vazio o campo de 'tudo o que teria sido possível ao sujeito dizer (mas que não diz)' ou o campo de 'tudo a que se opõe o que o sujeito disse'. Esta zona do 'rejeitado' pode estar mais ou menos próxima da consciência e há questões do interlocutor que o fazem reformular as fronteiras e re-investigar esta zona (p. 175-176).

Por ela ser circunscrita, quando o sujeito-autor da enciclopédia afirma $\mathrm{X}$ e não $\mathrm{Y}$, quando ele apresenta determinados verbetes e não outros, ele constrói discursivamente na enciclopédia um fechamento imaginário dos sentidos, que faz com que os saberes nela expostos sejam tomados em uma "relação de evidência entre e sobre si mesmos", conforme entende Morello (2003, p.122). E que faz também com que se produza a ilusão de que todas as 'coisas a saber' se encontram nos verbetes das enciclopédias.

Embora a totalidade numérica dos saberes seja almejada, sabemos que isto não é possível. O que o enciclopedista apresentaria, portanto, seria um universo de 'coisas a saber' que projetaria no espaço uma leitura do mundo. Por conseguinte, não haveria na enciclopédia a apreensão de todos os saberes já formulados, mas sim a construção discursiva de um 'todo'. A enciclopédia seria, pois, um conjunto fechado, delimitado e estruturado de saberes, como um 'todo circular', que se fecha sobre si mesmo. 
Em última instância, seria a ideologia que representaria a saturação, o efeito de completude que, por sua vez, produziria o efeito de evidência (cf. Orlandi, 2007) de que aquelas 'coisas a saber' presentes nas enciclopédias seriam, de fato, todos os saberes existentes. É sob esta perspectiva que existiria uma totalidade, ainda que ilusória, nas versões limitadas espacialmente das enciclopédias. E é sob esta perspectiva, igualmente, que poderíamos conceber tal instrumento tecnológico a partir da metáfora do 'círculo que se fecha', tal como a etimologia da palavra ${ }^{6}$ enciclopédia nos sugere.

O que o discurso sobre a Wikipédia estaria produzindo seria o efeito de sentido de que, pelo fato desta se apresentar no espaço virtual, seria possível à Wikipédia disponibilizar não um conjunto legitimado e estabilizado de saberes, mas a soma de todos os saberes existentes. Como se quanto maior a quantidade de verbetes na Wikipédia, maior a possibilidade de se chegar ao 'saber total'. Em outras palavras, se antes os sujeitos concebiam estar diante do 'saber total' porque a materialidade da enciclopédia limitava, no espaço e no tempo, sua extensão e seu campo de abrangência, fazendo com que estes tomassem as 'coisas a saber' ali apresentadas como a 'totalidade dos saberes' existentes, hoje tal interpretação estaria se delineando justamente pelo fato de a Wikipédia possibilitar que mais e mais saberes sejam disponibilizados a todo momento em seu escopo. O que estaríamos presenciando seria uma mudança no modo como este 'efeito imaginário' funcionaria na atualidade. A ilusão da totalidade não seria mais produzida pelo 'efeito de fechamento' (cf. Orlandi, 2004) da enciclopédia, mas sim pelo permanente 'alargamento' da Wikipédia.

A compreensão a que chegamos, no entanto, foi oposta a esta que se faz presente neste discurso brevemente mencionado. Ainda que a abertura à edição colaborativa da Wikipédia produza a ilusão da totalidade numérica, o fato de a Wikipédia se colocar como o sítio virtual cujos contornos estão sempre se refazendo seria a própria afirmação da impossibilidade de ela vir a ser a 'enciclopédia completa'. Tal como afirma Dias' (2007), na Wikipédia, de "link em link não há círculo que se feche, mas sentidos que se abrem e se expandem. Cada link é uma cicatriz no sentido: a marca da incompletude".

Não havendo a possibilidade de um fechamento imaginário dos sentidos na Wikipédia, ela não poderia ser concebida como um círculo que se fecha, mas sim como uma rede que se abre, indefinidamente. Uma vez que existiria esse 'deslizamento de sentido' do círculo à rede, a questão da totalização dos saberes nas enciclopédias colocar-se-ia de outra forma. Se havia a construção discursiva de uma totalidade (ilusória) dos saberes nas enciclopédias limitadas espacialmente, na Wikipédia, diversamente, tal

6 'Enciclopédia' é um termo latinizado a partir do grego 'eu-kuklios paideia', que quer dizer o 'círculo (kuklios) perfeito (eu) do conhecimento ou da educação (paideia) (Pombo, 2006).

${ }^{7}$ Comentário da Prof. ${ }^{a}$ Dr. Cristiane Dias na arguição da Dissertação em questão. 
construção não existiria, pois não havendo um 'fim', um ponto final, não haveria como construir um 'todo'.

Tendo em vista esta distinção primeira, a qual seria, em nossa perspectiva, o principal diferencial da Wikipédia em relação às enciclopédias, entendemos ser necessário, a fim de sustentar essa passagem do circulo à rede, apresentar outros pontos em que tal diferenciação ocorreria.

Como não poderíamos deixar de enfatizar, a rapidez, presente na etimologia do vocábulo ${ }^{8}$ Wikipédia, seria um dos pontos de distanciamento em relação às enciclopédias. O resultado da procura por um determinado verbete, por exemplo, é apresentado em alguns décimos de segundo. Até mesmo na edição de seus verbetes textualizar-se-ia esta rapidez, pois estes podem ser criados, modificados ou mesmo eliminados em questão de segundos ou minutos.

Juntamente com esta primeira característica, estaria uma outra, também central: a autoria colaborativa. Por possibilitar que um número maior de sujeitos faça parte da escritura de seus verbetes, com a Wikipédia estaríamos diante do que Pêcheux (1997a) denominou de "re-organização social do trabalho intelectual". Não é mais o monge ou o teólogo da Idade Média, o humanista do século XVI, o filósofo iluminista, ou ainda uma equipe de especialistas que elaboram as 'coisas a saber'. Neste 'sítio significante', os saberes são postos em circulação por diferentes sujeitos que se encontram em diferentes lugares e momentos.

Essa reorganização, que faria com que o que pode ou não ser dito em um instrumento tecnológico como este obedecesse a outros critérios que não os que comumente permeariam a elaboração de tal obra, levaria, por conseguinte, a uma redefinição do que é ou não relevante de ser apresentado, pois a relevância dos saberes na Wikipédia seria de outra ordem. Neste sítio virtual, verbetes como 'Daniela Ciccarelli' e 'Pokémon', por exemplo, estariam ao lado de verbetes como 'Emmanuel Kant', 'Revolução Industrial', 'Análise de Discurso', etc. Instaurar-se-ia uma equivalência destes saberes, o que, consequentemente, levaria a uma outra/nova forma de se compreender o que é considerado um 'saber enciclopédico'. E esta outra/nova compreensão seria, em nosso entendimento, uma terceira diferença envolvendo a Wikipédia e as enciclopédias então existentes.

8 A palavra Wikipédia é construída a partir da união da palavra wiki, do havaiano wiki wiki, que quer dizer 'veloz', 'rápido', e paideia, do grego, que quer dizer 'conhecimento'. Wikipédia remeteria, portanto, ao 'conhecimento veloz, rápido'. 


\section{Conclusão}

Serres (2005, p. 141) afirma que "quando uma coisa muda de escala, ela frequentemente muda também de natureza". Para nós, a configuração da Wikipédia, a qual possibilita que inúmeros saberes que já faziam ou não parte de uma enciclopédia sejam apresentados em seu escopo, faz com que haja uma modificação não somente no modo como estes saberes são postos em circulação, mas também em relação à natureza destes saberes. Isto é, a própria definição do que pode ser um 'saber enciclopédico' estaria sendo (re)significada com a Wikipédia.

Nesse sentido, a Wikipédia não deixa incólume o que é um 'saber enciclopédico' e tampouco a própria memória de enciclopédia. Ela desloca sentidos, reformula toda uma maneira de conceber e de pôr em circulação os saberes e nos coloca diante do 'muito cheio', do excesso, que seria representado por seus vários milhões de verbetes que não cessam de aumentar.

Com a Wikipédia estaríamos, em última instância, diante de uma outra/nova forma do conjunto dos saberes que se delinearia na contemporaneidade, forma esta intrinsecamente relacionada ao momento histórico em que vivemos, um momento onde a lógica do mundo estaria se modificando devido, de um lado, à presença cada vez mais incisiva das novas tecnologias de informação e comunicação nos diversos âmbitos da sociedade e, de outro, à prática então dominante da dinâmica de mercado, que traria consigo a velocidade e a aceleração, características tão presentes na configuração deste sítio virtual e da Web como um todo.

\section{Referências}

DIAS, C. O falar de si como marca constitutiva de alteridade. In: SCHERER, A. E. (org.). Discurso: circulação, fragmentação e funcionamento. Santa Maria: PPGL, Laboratório Corpus, 2006.

MORELLO, R. Definir e linkar: em que sentido? In: ORLANDI, E. (org). Para uma enciclopédia da cidade. Campinas: Pontes, 2003.

ORLANDI, E. P. Interpretação. 4.ed. Campinas: Pontes, 2004.

. As formas do silêncio. 6.ed. Campinas: Unicamp, 2007.

PÊCHEUX, M. Discurso: estrutura ou acontecimento. Traduzido por E.P. Orlandi. 2.ed. Campinas: Unicamp, 1997.

. Ler o arquivo hoje. In: ORLANDI, E. (org.). Gestos de Leitura: da história no discurso. Traduzido por B. Mariani [et.al.]. 2.ed. Campinas: Unicamp, 1997a.

PÊCHEUX, M.; FUCHS, C. A propósito da análise automática do discurso: atualização e perspectivas. In: GADET. F. e T; HAK. (orgs.). Por uma análise automática do discurso: uma introdução à obra de Michel Pêcheux. 3.ed. Campinas: Unicamp, 1997. 
POMBO, O. O Enciclopedismo Renascentista e Barroco. Disponível em: <http://www.educ.fc.ul.pt/hyper/enciclopedia/cap2p3/encbar.htm>. Acesso em 26.set.2006.

SERRES, M. O incandescente. Traduzido por E. de A. Carvalho; M. P. Bosco. Rio de Janeiro: Bertrand Brasil, 2005. 